Proceedings of the Institution of
Civil Engineers
Bridge Engineering 158
December 2005 Issue BE4
Pages 193-199
Paper 14242
Received 04/05/2005
Accepted 02/08/2005
Keywords:
bridges/steel structures

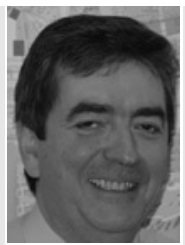

Ángel C. Aparicio Professor, Civil Engineering School, Barcelona, Spain

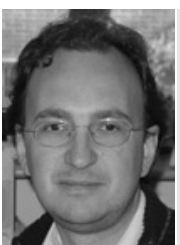

Gonzalo Ramos Associate Professor, Civil Engineering School, Barcelona, Spain

\title{
Footbridge over the Sant Adria Marina in Barcelona, Spain
}

\section{Á. C. Aparicio MSc, PhD, MACHE, MFIB, MIABSE and G. Ramos MSc, PhD, MACHE, MFIB, MIABSE}

This paper presents a description of a continuous truss footbridge comprising two spans, one of $140 \mathrm{~m}$ and the other $50 \mathrm{~m}$. The bridge crosses the Sant Adria Marina, close to Barcelona. The width of the deck is $6 \mathrm{~m}$ and the depth of the two trusses, which form the bridge, range between 6 and $10 \mathrm{~m}$. Main innovations are the use of recycled aggregates for concrete in the approach slab deck, the use of silica fume concrete for the pavement which performs well from the strength, durability and aesthetic points of view and the formal exploration of irregular longitudinal layouts in truss bridges. This formal exploration resulted in the creation of an internal space extremely pleasant for people and avoiding any tunnel sensation. Moreover, the absence of dynamic loads and the light live load allowed the trusses to be designed without using gusset plates.

\section{INTRODUCTION}

The footbridge connects both sides of the Sant Adria Marina, very close to the city of Barcelona, in a newly developed area (Fig. 1). It allows pedestrians to cross from a huge esplanade surrounded by convention and exhibition centres, where the Barcelona Forum 2004 took place, to a park. The bridge crosses over the basin of the marina, and is a two-span bridge with spans of approximately 140 and $55 \mathrm{~m}$.

\section{DESIGN PROCESS}

The bridge was designed to connect two points separated by $200 \mathrm{~m}$ and at different heights, $20 \cdot 2$ and $10 \cdot 3 \mathrm{~m}$ above water level at the esplanade and at the park, respectively. It was designed to achieve the conditions needed for wheelchair access, which was in this case an important design condition because of the resultant slope between the two ends of the footbridge.

Other requirements included the need for the bridge to connect with the roof of the Capitania Building, $14 \mathrm{~m}$ above sea level and clearances for the marina needed an air space of height $16.40 \mathrm{~m}$ over a length of $25 \mathrm{~m}$, to allow medium-sized yachts to enter the harbour. The outer side of the harbour is reserved for large yachts.

After considering several solutions including one long-span bridge using high-strength concrete and a medium-span bridge with a composite deck it was decided to adopt a steel truss design with two spans, having a long span over the sea. The steel truss allows for a greater clearance over the water and also for the possibility of mooring larger boats under it.

The preliminary solution was a footbridge formed by two Warren constant-depth trusses and a platform between them at the bottom chord level. However, an adaptation was made to the design to obtain, using the longitudinal top chord layout of the bridge, a movement sensation similar to the view of the mountains that can be seen when looking towards Barcelona from the sea.

Different polygonal geometries were drawn for each upper chord of the trusses, which resemble the nearby mountains. The bottom chords were also polygonal because they were adapted to a geometry which would allow for wheelchair access. The movement idea was achieved but it needed to be structurally refined.

During the design process the trusses were changed from constant-depth beams to variable-depth beams and, moreover, each truss was developed to have a different longitudinal layout. The south truss, closer to the open sea, has a larger depth over the intermediate support and a shorter depth at mid-span than the north truss, which is closer to the land. This solution, which was structurally acceptable, produced the desired visual effect and also created a ceiling (formed by diagonals connecting both upper chords) with a wave shape that people can enjoy, and avoided any tunnel sensation, which can often be a problem for such a long footbridge (Fig. 2).

\section{DESCRIPTION OF THE SOLUTION}

The footbridge is formed by a platform, $5 \mathrm{~m}$ wide supported by two irregular Warren trusses, one on each side. The platform is situated at the bottom chord level and both chords are connected by a horizontal truss system. Longitudinally the structural scheme is a two-span continuous beam, which spans 140 and $55 \mathrm{~m}$ for the north truss and 141 and $56 \mathrm{~m}$ for the south truss. The north truss has a depth of over $8 \mathrm{~m}$ over the support with a mid-span depth of $8.5 \mathrm{~m}$. On the opposite side, the south truss depth is $6 \mathrm{~m}$ at mid-span and $10 \mathrm{~m}$ over the intermediate support.

There are two levels of elements, called the main truss and the secondary truss. The main truss mesh is always 6,12 or $18 \mathrm{~m}$ 


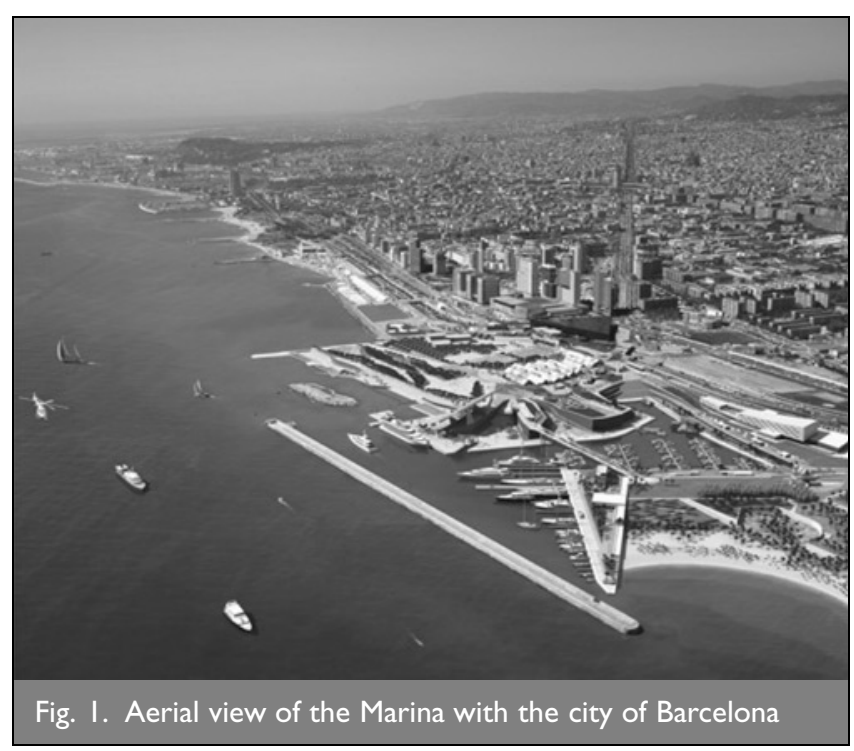

long. The longest diagonals (more than $18 \mathrm{~m}$ ) are in tension and close to the supports and the shorter ones are in compression and in the mid-span area. In this way any possible instability of the elements is controlled and the use of an irregular truss is made possible. Furthermore, this enables the long tension diagonals and short compression diagonals to be of an economic section size. Even though many load cases were studied, no diagonals of the main trusses were found to be subjected to reversal of loading.

The secondary truss, with $6 \mathrm{~m}$ modules, has several functions.

(a) The first one, and the main function, is to control the bending of the bottom chords produced by the footway loading.

(b) It controls the bending due to self-weight of the upper chords and reduces the buckling length of the compression chord in the span.

(c) It closes the structural box.

(d) Some elements, which do not work in a Warren truss, help to reduce the lateral movements of the chord due to wind and control possible lateral buckling.

Figures 3, 4 and 5 show the global geometry of the trusses, piers, and abutments, a plan of the footbridge and the section at the intermediate pier respectively.

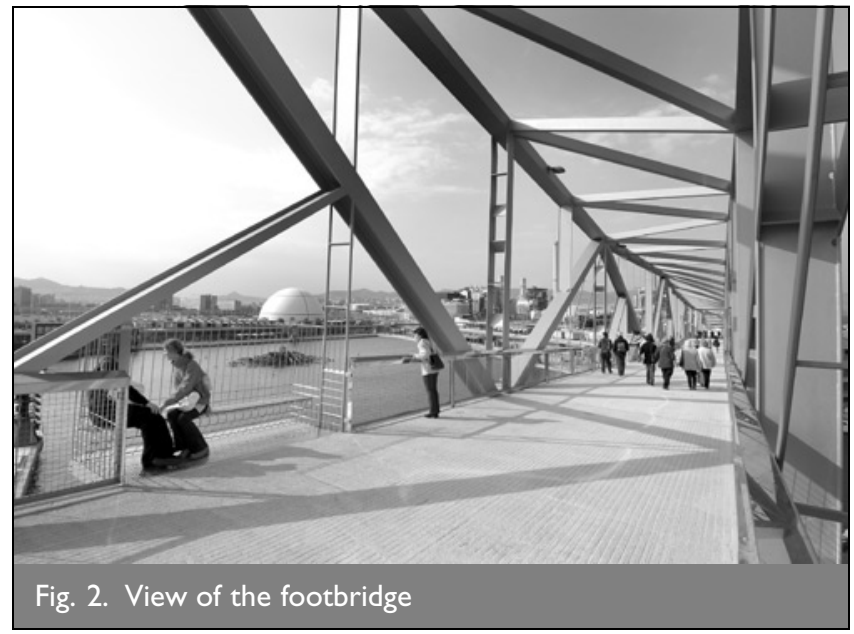

The upper and bottom chords are steel boxes $500 \mathrm{~mm}$ wide and $400 \mathrm{~mm}$ deep. The thickness of the plates varies between 15 and $40 \mathrm{~mm}$, depending on the forces. The vertical studs of the main truss are also boxes but with thinner plates because, even though the transverse inertia is important, they are affected by secondary forces.

The secondary mesh is much lighter with open sections of $50 \mathrm{~mm} \times 20 \mathrm{~mm}$ solid-linked bars. All the steel is high-yield steel to BS EN 10025 S355 J2 G3 (formerly Grade BS 4360 50D).

After several alternatives were considered for the footway, taking both architectural and economical aspects into consideration, trapezoidal high-strength, precast concrete elements were chosen, supported on the bottom beams connecting both bottom chords. The beams are wide flange (HEB 400).

The contractor proposed a change to this solution and pretensioned, precast concrete $100 \mathrm{~mm}$ deep was used which, after placing, required a further $100 \mathrm{~mm}$ of in situ concrete to be added over the slabs. The slabs, with a length of $6 \mathrm{~m}$, were supported only by the shorter footway beams, not by the diagonals, this being the case even after creep. To avoid such contact at the diagonals, the support has a mortar bed of $40 \mathrm{~mm}$ confined with angular sections.

Because the $6 \mathrm{~m}$ span of the slabs is only large enough for $100 \mathrm{~mm}$ depth they have a reinforced concrete truss built in that assists in the support of the in situ concrete and concrete equipment. The in situ concrete has the addition of silica fume in order to obtain the desired impermeability. The upper layer of concrete is printed with a plastic, achieving with only one material the resistance, durability and aesthetic functions required by the footbridge floor.

The ceiling beams, which transmit the wind effects to the frames situated at the supports and also control buckling of the upper chords of the trusses, are commercial box sections of $300 \mathrm{~mm} \times 300 \mathrm{~mm}$ and $10 \mathrm{~mm}$ thickness.

The footbridge is supported at the esplanade side on a reinforced concrete slab which covers the Marina Seca. It is a building where small boats are stored in shelters. The plan view of the slab is a trapezoid. The width of the slab varies from 7 up to $22 \mathrm{~m}$. This geometry is achieved by the use of in situ reinforced rather than precast concrete. Its span is $24 \mathrm{~m}$ with a depth of $2.5 \mathrm{~m}$, this being due to the need for architectural continuity with the Marina Seca. This span-to-depth ratio allows the slab to be constructed with reinforced concrete avoiding the need for stressing. Its cross-section is a multi-cellular box. It is innovative in that the concrete used for the bottom flange and the external webs, which are in close contact with the marine environment, incorporated recycled aggregate with $20 \%$ of the large aggregate being replaced with aggregate obtained from a demolished building.

The slab is supported at the Marina Seca by a reinforced concrete frame with three piers, each founded on six precast piles. Each pile is $30 \mathrm{~m}$ long and has a cross-section of $300 \mathrm{~mm} \times 300 \mathrm{~mm}$. The footbridge and the slab are supported by two piers clamped to the slab and with a foundation of six piles, $40 \mathrm{~m}$ long and $1500 \mathrm{~mm}$ in diameter. 


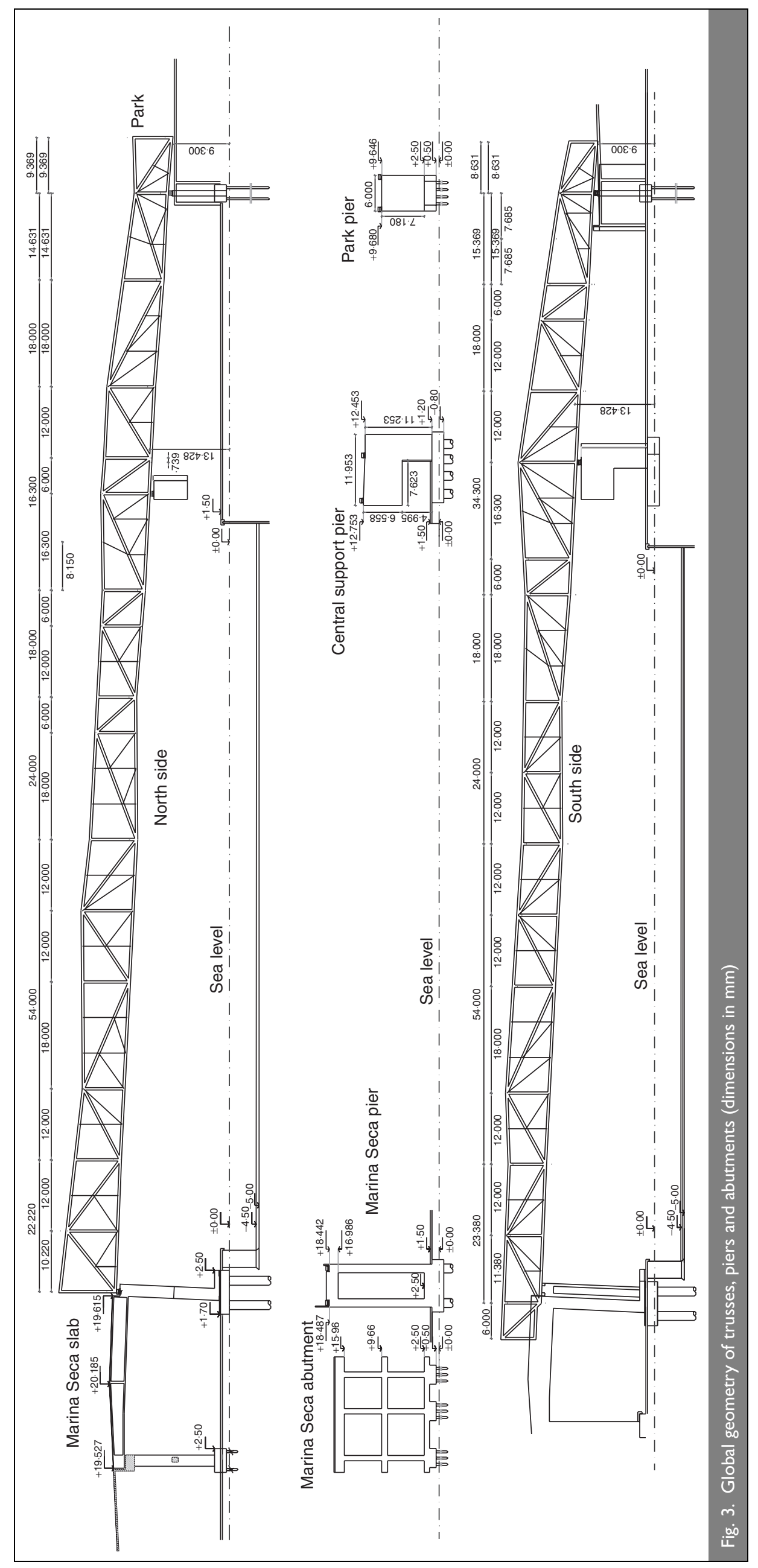




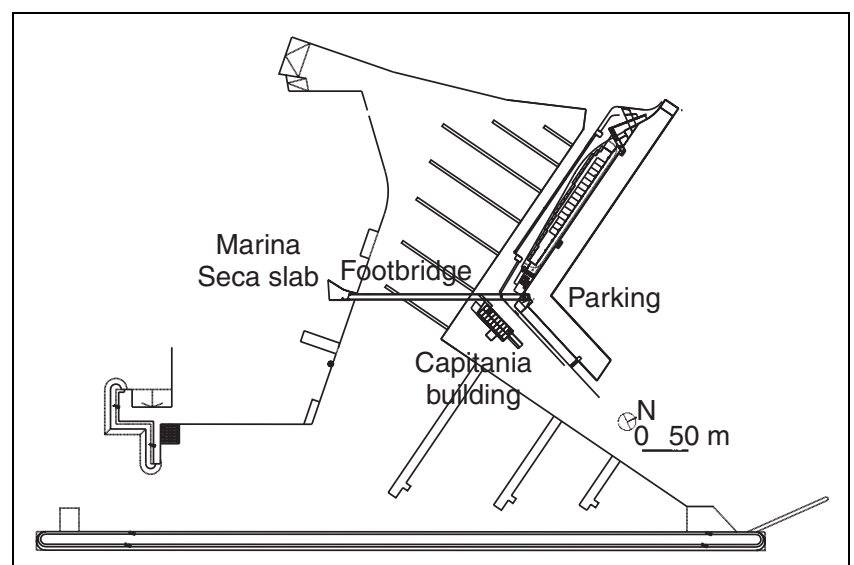

Fig. 4. Plan of the footbridge crossing the marina

The intermediate pier of the footbridge is an inverted ' $L$ ' shape formed in reinforced concrete. The cantilever allows headroom of $4 \mathrm{~m}$ for vehicles to reach their moorings. Its design is integrated with the building, and in particular with its north façade, which results in its skew, and it supports not only the footbridge but also the upper façade beam of the building. Its foundation is formed by five piles, $40 \mathrm{~m}$ long and $1500 \mathrm{~mm}$ in diameter, each one supporting a $6000 \mathrm{kN}$ in-service loading.

The abutment at the park side is a small pier which is hidden in a corner of the parking area. It is simply a wall of $6 \mathrm{~m} \times 1 \mathrm{~m}$ cross-section supported by eight precast piles of $400 \mathrm{~mm} \times 400 \mathrm{~mm}$ section, $30 \mathrm{~m}$ long which are mainly in tension. The vertical reinforcement of the pier, which is also in tension, has a low service stress in order to reduce the vertical movements of the bearings and the crack widths. Control of crack widths is essential in a marine environment to ensure durability.

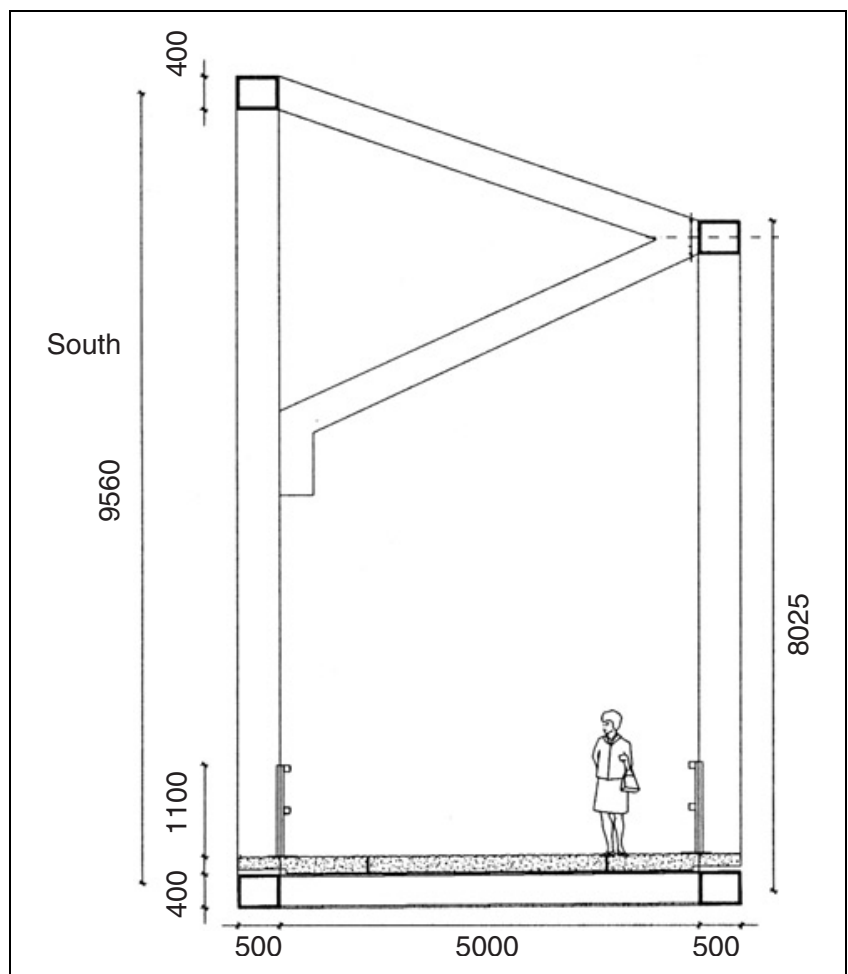

Fig. 5. Section at the intermediate pier (dimensions in $\mathrm{mm}$ )
The bearings comprise conventional pot bearings and clamped pot bearings capable of resisting tension. The bearings are bolted to thick steel plates situated under the bottom chords. The fixed bearing is located at the intermediate pier on the south side.

The other bearing at this pier is free sliding. At the pier, hidden in the parking area, two clamped pot bearings are used. One central sliding guided bearing is used at the south side and a free sliding one at the other side. Both bearings at the Marina Seca are free sliding. The wind reaction is resisted by means of a central sliding guided bearing located at the pier cap.

\section{ASSEMBLING}

Each element of the trusses was fabricated at a factory in Vitoria and transported by truck to Barcelona where they were assembled. From the beginning of the works at the Forum site it was planned to use an earth embankment crossing the marina in order to improve the movement of trucks and other machinery. This path was enlarged and made parallel to the footbridge so that it could be used as a platform to assemble the trusses. The assembly procedure was carried out in the following manner.

(a) Each truss was divided into three segments each around $70 \mathrm{~m}$ long and $80 \mathrm{t}$ in weight. The first segment went from the Marina Seca support to mid-span. The second one went from mid-span to the intermediate support and the third one from the intermediate support to the park abutment.

(b) Each segment was assembled horizontally over the path, the north side on top of the south side supported by temporary supports formed by short European light IPE 500 beams, making the labour conditions easier and increasing the safety and productivity of the work (Fig. 6).

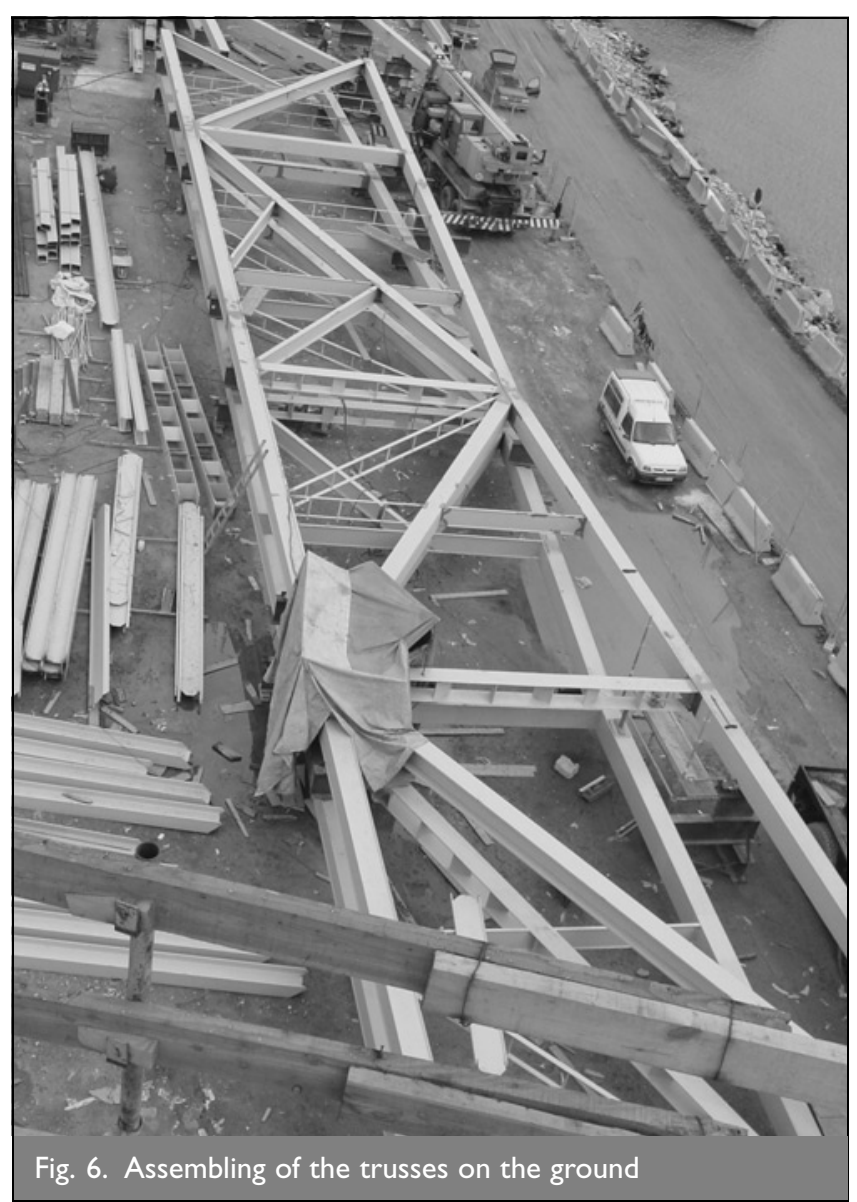




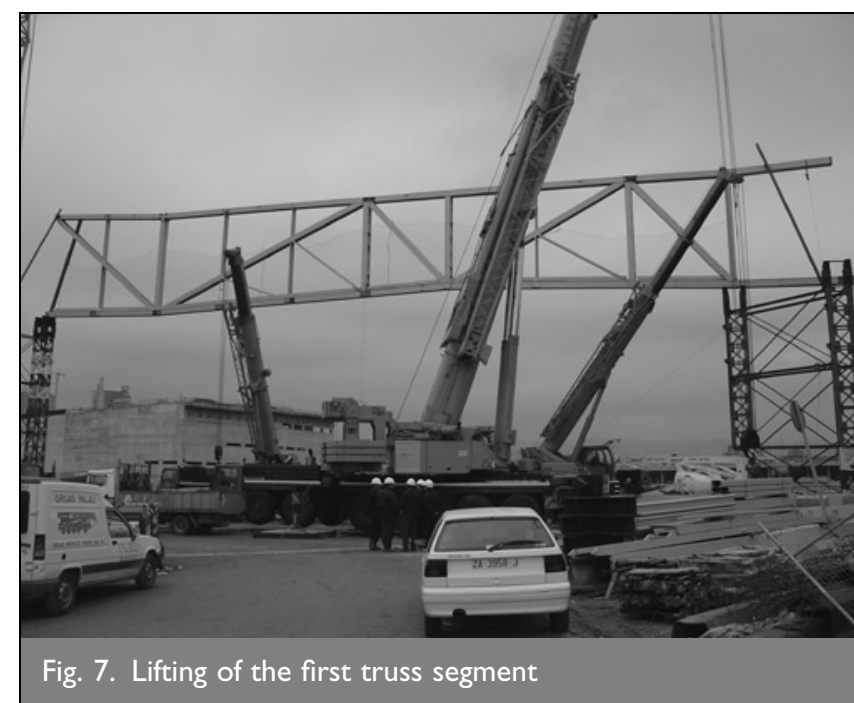

(c) After the segments were assembled, each one was elevated. First the north truss, then the south one beneath it (Fig. 7). The first segments (north and south) were supported on temporary bearings on the Marina Seca pier cap and on temporary supports founded on the soil path (Fig. 8). The second segment was supported on the same temporary support and on another one located very close to the intermediate pier. The third one was supported by the intermediate pier and the park abutment, also on temporary bearings allowing regulation.

(d) Every segment was lifted by four cranes, two heavy cranes that lifted the truss from the nodes of the upper chord and two lighter cranes which helped to lift the segment horizontally and then turn it vertically. The two lighter cranes were attached to nodes of the bottom chord of the truss.

(e) Once in a vertical plane, each segment was located over the temporary supports, as described earlier and was stabilised transversally by means of beams.

(f) When both segments, north and south sides, were placed, the beams forming the floor and the ceiling were assembled in situ.

(g) Finally the three segments forming each truss were welded at each chord. Then the temporary supports were removed and a lowering of the Marina Seca support was executed.

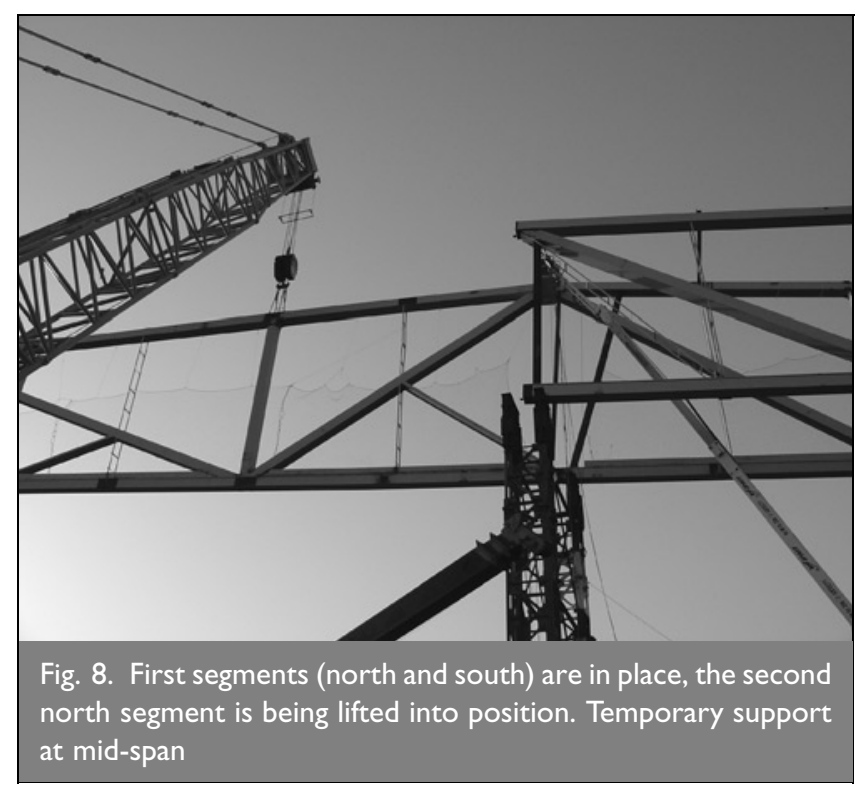

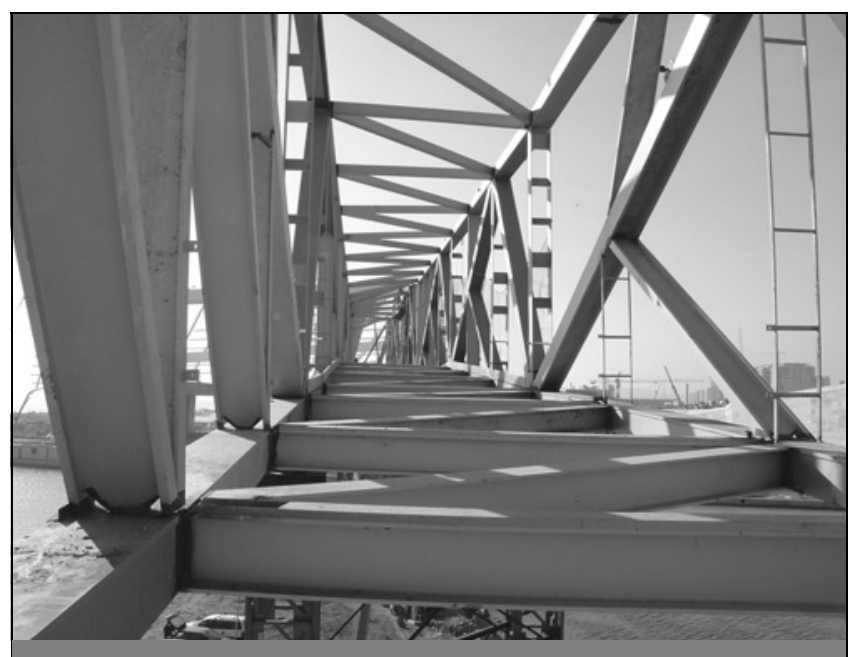

Fig. 9. The steel structure is completed. The precast concrete slab forming the platform will be supported by the floor beams

The aim of this movement was to obtain the bending moments due to self-weight expected in the design, which were calculated assuming a different assembly process.

Figures 6 to 10 show different stages of the assembly process.

When the steel structure was complete, the precast, prestressed concrete slabs were craned into position. A reinforcing steel mesh was added and a $100 \mathrm{~mm}$ in situ silica fume concrete was poured. In order to obtain a textured pavement surface the concrete was 'printed'.

Finally the concrete pavement was painted with a resin, stainless steel barriers were placed at the sides of the deck and some balconies were added. The balconies give a suggestion of the high-rise buildings of this artificial landscape, simulating the city and the mountains.

The following external protection measures were used for the steelwork

(a) Sand blasting: Sa $21 \frac{1}{2}$ ISO 8501-1 with roughness between 30 and $50 \mu \mathrm{m}$.

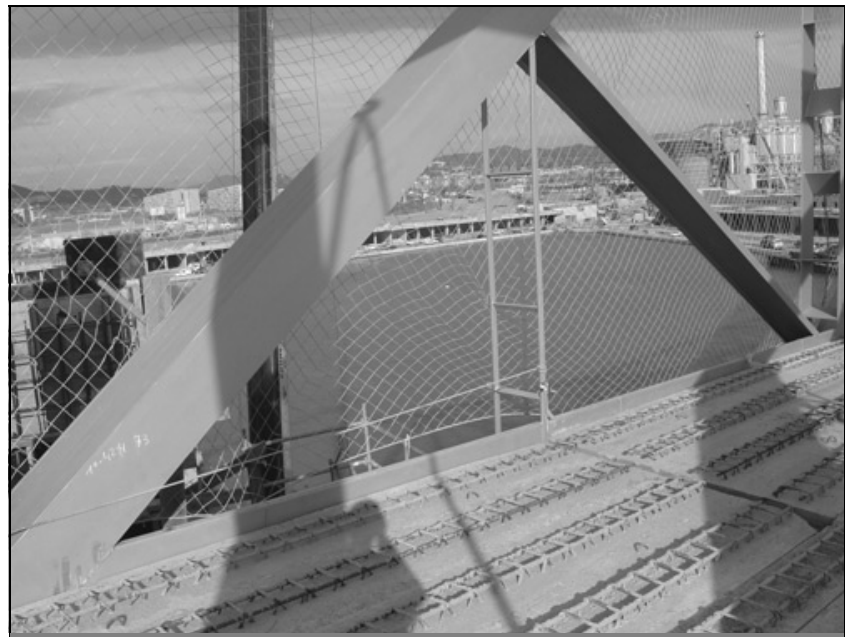

Fig. 10. The precast concrete slabs before a further $10 \mathrm{~cm}$ of in situ concrete is placed 


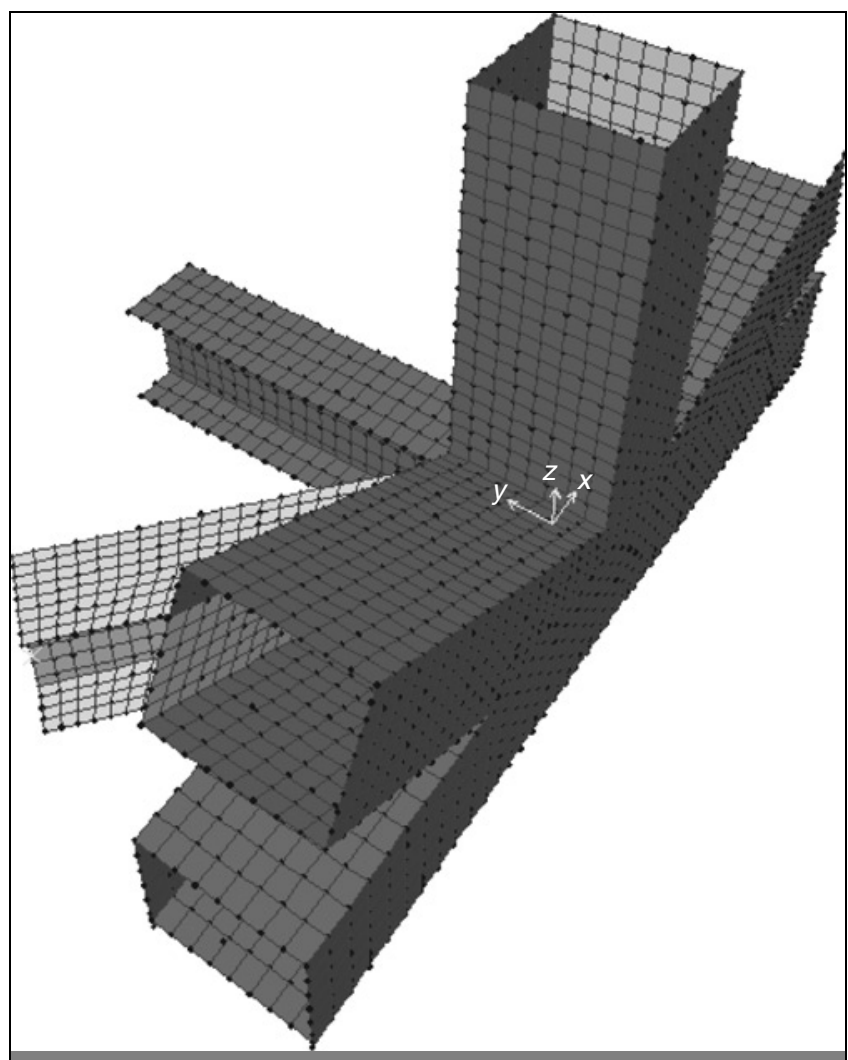

Fig. II. Three-dimensional view of the finite-element model

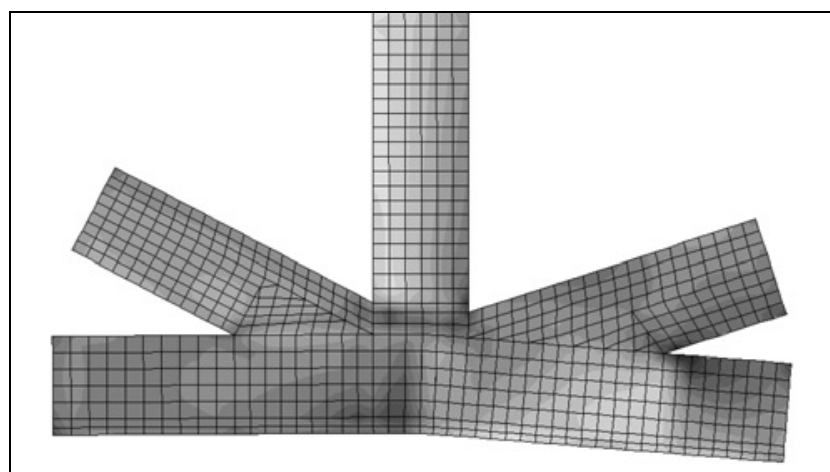

Fig. 12. Von Mises stresses at the joint. The maximum stress is $340 \mathrm{MPa}$ (b) Epoxy-zinc coating, SSPC-Paint (Standard Specification of Painting and Coating from the Society of Protective Coatings) 20 type 11, dry layer thickness $40 \mu \mathrm{m}$.

(c) Epoxy-polyamide coating SSPC-Paint 22 Intermediate, dry layer thickness $90 \mu \mathrm{m}$.

(d) Aliphatic polyurethane enamel, type V of SSPC-P5-Guide 17, dry layer thickness $35 \mathrm{~m}$.

No measures to prevent collision with tall-masted boats were adopted.

\section{STRUCTURAL ANALYSIS}

The bridge was modelled as a three-dimensional frame with rigid nodes. In this way, the secondary moments were taken into account in the analysis and in the verification of the sections. The loadings considered were the self-weight of the steel structure, dead loads (pavement, barriers), live loads of $4 \mathrm{kN} / \mathrm{m}^{2}$ for people and $1 \mathrm{kN} / \mathrm{m}^{2}$ for eventual urban equipment (such as benches), horizontal wind forces and temperature. EuroCode 3 was used as the design code. The global stability was verified using non-linear analysis.

It was important to study the behaviour of the nodes because of their unconventional geometry. For this purpose, one of the most typical nodes, with very high forces and moments acting on it, was studied using shell finite elements (Fig. 11).

The node was studied for several load combinations and vertical, horizontal and tangential stresses were obtained for every plate, as well as von Mises stresses (Fig. 12). Thus it was possible to control the effect of the changes in the thickness of the plates at the nodes and, at the same time, obtain design criteria for verifying, in an approximate way, the rest of the nodes of the structure.

It was also very important to control the stresses in the direction of the thickness of the plate to avoid problems of lamellar tearing. The low value of these stresses, about $21 \%$ of the yield stresses, thanks to the inclination of the diagonals, allowed the desired design of nodes to be achieved without gusset plates. Obviously, this was possible because the bridge was a footbridge without large loads, dynamic loads or fatigue problems.

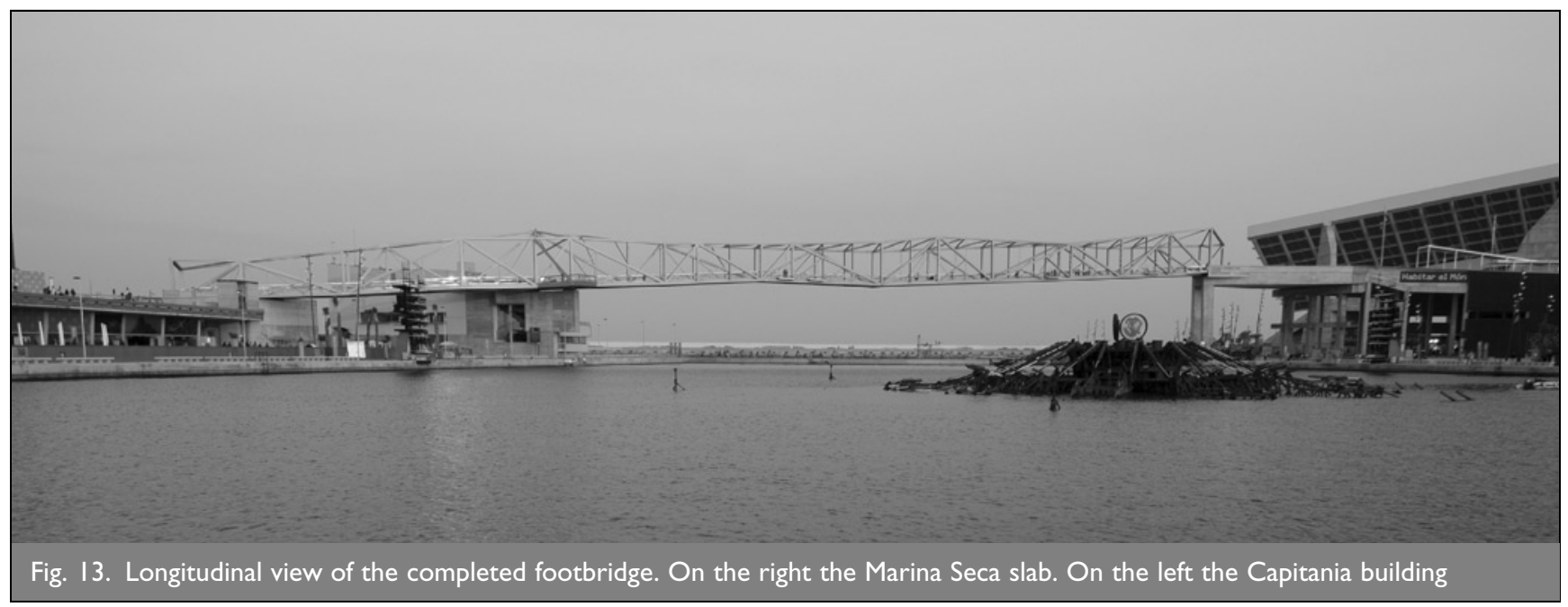



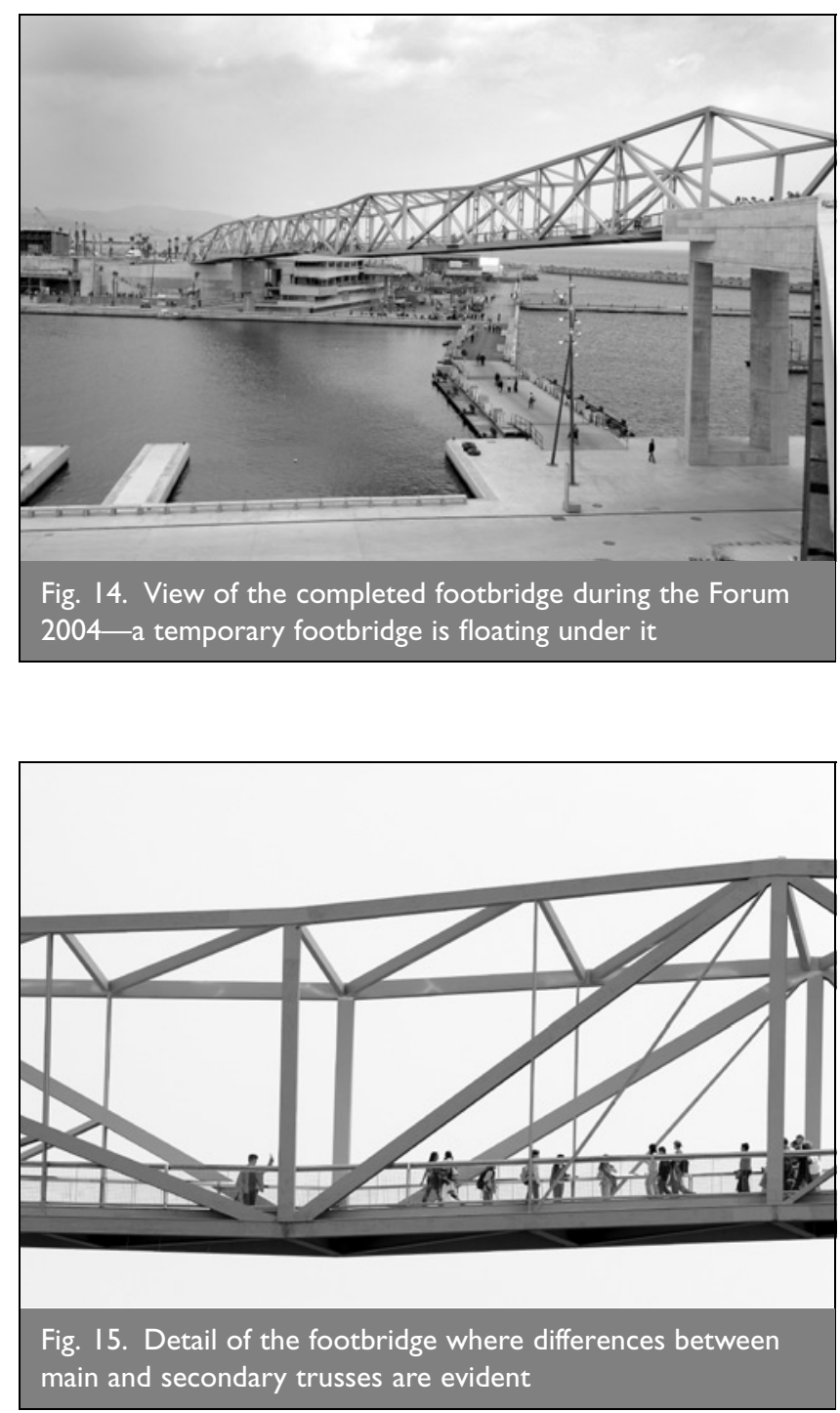

\section{STATIC LOAD TEST}

The static load test was executed by means of large bags full of sea water achieving a global load of $60 \%$ of the characteristic live load. Two load combinations were verified. The first one loaded only the main span, looking for maximum bending moment at mid-span. The second one loaded all of the deck in order to obtain maximum bending moments at the intermediate support. The measured displacements were very close to the expected and the movement was completely recovered upon removal of the loads.

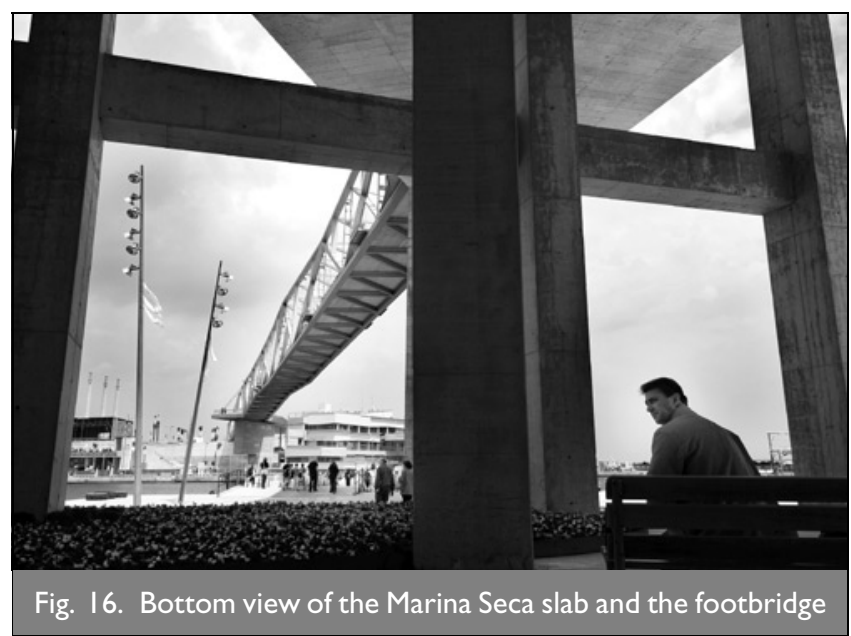

\section{CONCLUSION}

The total cost of the footbridge was $€ 1.7$ million, which represents about $€ 1417 / \mathrm{m}^{2}$. Main innovations were the use of recycled aggregates for concrete in the Marina Seca slab deck, the use of silica fume concrete for the pavement which performs well from the strength, durability and aesthetic points of view and the formal exploration of irregular longitudinal layouts in truss bridges. This formal exploration resulted in the creation of an internal space which is extremely pleasant for the users and avoids any tunnel sensation. Moreover, the absence of dynamic loads and the light live load permitted the trusses to be designed without using gusset plates. Figs 13 to 16 show the completed footbridge.

\section{PERSONNEL AND COMPANIES INVOLVED}

Project authors: Ángel C. Aparicio Bengoechea and Gonzalo Ramos Schneider, Civil Engineers.

Architects: Mamen Domingo and Ernest Ferré.

Project managers: Victor Obradors and Alejandro Mir, Civil Engineers.

Main contractor of the footbridge: Construcciones Benjumea. Civil Engineers: Jordi Pérez and Javier Ballesteros.

Steel structure: URSSA.

Marina Seca slab deck: UTE conexión NECSO-RUBAU. Intermediate and park piers: ACS.

Quality control of steel structure: ATISAE.

\section{What do you think?}

To comment on this paper, please email up to 500 words to the editor at journals@ice.org.uk

Proceedings journals rely entirely on contributions sent in by civil engineers and related professionals, academics and students. Papers should be 2000-5000 words long, with adequate illustrations and references. Please visit www.thomastelford.com/journals for author guidelines and further details. 